\title{
JAIME QUEZADA: NACER FUERA DE LA LEY. ILEGITIMIDAD Y JUSTICIA*
}

\author{
JAIME QUEZADA: TO BE BORN OUT OF THE LAW. \\ ILLEGITIMACY AND JUSTICE \\ Claudio Guerrero Valenzuela \\ Pontificia Universidad Católica de Valparaíso. Valparaíso, Chile \\ cmguerrev@gmail.com
}

\begin{abstract}
Resumen: Este artículo propone que la infancia en la poesía de Quezada forma parte de un proyecto que intenta reescribir la historia hogareña de niños y niñas a partir de la denuncia y destrucción del falso principio social en el cual se insertan para construir sobre sus ruinas una fábula que es signo de rebeldía, disidencia y libertad. Representándose a sí mismo como un niño agredido, huérfano e ilegítimo discursea sobre su infancia, desde la intrahistoria, para plantear alternativas a las normas y costumbres que la Historia oficial dicta, no trata o apenas soslaya. De este modo, su fábula adquiere sentido práctico, en cuanto el mensaje moralizante que deja es un acto de justicia para esta infancia doblemente vulnerada, al estar también fuera de la ley del lenguaje.
\end{abstract}

Palabras clave: Poesía chilena, infancia en la literatura, orfandad en la poesía chilena, ilegitimidad familiar.

Abstract: This article proposes that the childhood in Quezada's poetry forms a part of a project that tries to rewrite the homeloving history of kids from the report and destruction of the false social principle in which they are inserted to construct on his ruins a fable that is a sign of rebelliousness, dissent and freedom. Being represented to his self as an attacked, orphan and illegitimate child speech about his childhood, from the personal history, to raise alternatives to the procedure and customs that the official History dictates, it does not treat or scarcely has it ignored. Thus, his fable ac-

* Este trabajo forma parte del proyecto "Representaciones de infancia en la poesía chilena de segunda mitad del siglo XX”, Fondecyt $\mathrm{N}^{\circ} 11121276$. 
quires practical sense, in all that the moralizing message that stops is an act of justice for this doubly damaged childhood, on having been also out of the law of the language.

Keywords: Chilean poetry, childhood in literature, orphanhood in chilean poetry, family illegitimacy.

Recibido: 20.01.2016. Aceptado: 22.06.2016

\section{El juicio de la herencia}

$\mathrm{L}$

A TRAYECTORIA POÉTICA de Jaime Quezada (1942), desde la creación del grupo Arúspice en Concepción ${ }^{1}$, ha estado signada por una particular manera de poetizar la realidad que, tempranamente, trató de desligarse de toda corriente principal dentro de los cauces de la poesía chilena de los años sesenta. A saber, respetuoso de la antipoesía de Parra, del larismo de Teillier y del neovanguardismo de Lihn y Millán, la poesía de Jaime Quezada tiene por característica particular proponer una voz propia, fundada especialmente en la idea de un regreso fundacional que permita que la escritura tenga un sentido en el presente.

La necesidad de arraigo, de enraizarse en un álbum de familia, una casa, un pueblo, forma parte de un plan que intenta reescribir la infancia como un tiempo y un espacio desde donde es posible fundar una nueva historia con un sentido proyectivo, revitalizante, para el presente de la escritura. De este modo, dando pie a una idea de circularidad refundante, el hablante de gran parte de la poesía de Quezada realiza un recorrido por el mundo familiar para denunciar todo orden y normatividad representada en las figuras del Padre y la Cultura (la Ley, la amenaza de castración) con la finalidad de destruirla y construir sobre su ruina, sobre sus restos, una fábula de infancia. En el juicio de la herencia, de lo legado, el hablante termina siendo capaz de instaurar una infancia signo de rebeldía, disidencia y libertad

\footnotetext{
${ }^{1}$ El campo poético de los sesenta estuvo centrado especialmente en grupos literarios extracapitalinos: Tebaida (Arica), Arúspice (Concepción) y Trilce (Valdivia), fuera de los poetas dispersos, independientes, sin arrimo alguno a grupo literario, todos los cuales coexistían sin entrar en grandes conflictos entre sí y con la generación anterior, pero diferenciándose de ella por un mayor formalismo estilístico (Campos, 1987: 17). Formaron parte del grupo Arúspice los poetas Gonzalo Millán, Floridor Pérez y Silverio Muñoz, entre otros.
} 
contra los (falsos) principios y costumbres del hogar. Representándose a sí mismo como un niño agredido, huérfano y anónimo, vuelve atrás en el lenguaje y discursea sobre su infancia, desde la intrahistoria, para plantear alternativas a las normas y costumbres que la Historia oficial dicta, no trata o apenas soslaya. De este modo, su fábula adquiere sentido práctico, en cuanto el mensaje moralizante que deja es un acto reparatorio para toda infancia vulnerada, erigiéndose como posibilidad reconstructiva mediante la subjetividad discursiva del lenguaje.

A partir de esta hipótesis preliminar, haremos una revisión de la producción poética del autor considerando su primer libro y luego tomando como eje de nuestra argumentación el poemario que consideramos como el más logrado de todos, Las palabras del fabulador (1968), sin dejar de lado la mención a su obra posterior.

\section{Una irreparable orfandad}

El primer libro de Jaime Quezada, Poemas de las cosas olvidadas (1965), plantea como declaración fundante el rescate de las cosas olvidadas. Entre ellas, por cierto, la infancia. Sin embargo, dentro del plan general de su poética va a funcionar como antecedente para una elaboración posterior, en extenso. Destacamos, en este tránsito, que el poema está dedicado a una persona, cuyo nombre se dice que es María Alejandra, "que vive en el país de nunca jamás" (7), lo cual inmediatamente sitúa al lector en un plano intertextual próximo al Neverland del tradicional relato infantil Peter Pan (1911), de James Berrie (2006). Recordemos que los niños de este relato están solos o reniegan de sus padres y son llevados por Peter Pan y Campanita al país de los niños perdidos. El niño que aparece en estos poemas tiene algo de perdido, tiene algo de huérfano: es así como el hablante del "Poema del cielo triste" es un sujeto que ha esperado veinte años a un otro que suponemos su padre y llora "porque no puedo decirte que soy tu hijo" (14). En "Poema del cielo gris", en tanto, texto situado al lado del anterior dentro del plan del libro, el sujeto expresa: "Grises fueron mis sueños / y grises los ojos que nunca me amaron" (15). El sujeto ha heredado una historia de desamor, de cielos tristes y grises, que han impedido ver las cosas 
con alegría y esperanza, como cualquier niño normal. Como los niños de Peter Pan, el sujeto de estos poemas está solo, y por sobre todo se siente abandonado hasta tal punto que no puede nombrar al padre.

Esta orfandad expresada en la imposibilidad y prohibición de nombrar se metaforiza en el susto a la oscuridad de la noche que sentía cuando niño y que sigue sintiendo en el ahora adulto, ya que "ese mismo miedo aún no se me borra" (17). Miedo que es posible de apaciguar una vez que surge la luz, cuando amanece. Por eso, el amanecer viene "con un niño alegre de la mano" (24), es decir, con un sujeto niño que olvida y deja atrás con la luz del día sus miedos nocturnos. Pero esa felicidad matutina nunca lo es del todo porque "nunca ilumina / el cuarto vacío de mi madre pobre" (30), lo que señala, de entrada, que la huerfanía de este sujeto es algo que no tiene remedio, se trata de algo irreparable que tiene que ver también con el abandono de la madre producto de la ausencia benefactora del padre. La sociedad chilena de mediados de siglo reconoce en el padre la figura que debe sustentar económicamente el hogar. Su ausencia deriva no tanto en carencias emocionales, sino que por sobre todo en penurias económicas que se arrastran en el tiempo. Esto, desde un punto de vista material. Pero de manera simbólica también genera una leyenda (Salazar, 2006: 22), es decir, su ausencia lo convierte en un personaje mítico que inspira en el niño todo tipo de relatos, invenciones e imaginerías sin respuesta. Creemos que gran parte de los poemas de Quezada están asociados a esa construcción, a esa búsqueda que indaga en el origen a partir de una ausencia, un vacío de experiencia.

El abandono y la ausencia de filiaciones genera en el sujeto, asimismo, una temprana conciencia de la temporalidad, tal como se reafirma en el último poema de este primer poemario de Quezada, titulado "Elegía a la paloma que se ahogó en el río". El sujeto es esa paloma. Símbolo de inocencia y candidez, cada mañana esa paloma venía a beber las lágrimas de su madre. Ahora que está muerta, "en el fondo de tu muerte / un niño recoge caracoles en una cesta de mimbre" (37). El sujeto sabe que su infancia ha muerto y con ella su madre también y todo el orden anterior al lenguaje. Pero el sujeto sigue siendo esencialmente el mismo, un niño huérfano que interroga su identidad y su devenir, su existencia y su trascendencia: "El mismo niño / preguntándose / qué hay entre la eternidad y el vuelo” (37). Con esta pregunta concluye este poemario que introduce y esboza algunas 
de las principales problemáticas que plantea esta poesía: la pregunta por el Padre y el origen, al mismo tiempo que una búsqueda de trascendencia.

\section{Contra los principios y costumbre}

El segundo poemario de Jaime Quezada, Las palabras del fabulador (1968), Premio Alerce de la Sociedad de Escritores de Chile y dedicado a sus padres Claro José y Dulce María, está compuesta de tres secciones que en el plano general del libro forman una progresión que va, podríamos señalar, del silencio que busca romperse para nombrar y reconocer las cosas (Retrato Hablado), las experiencias y vivencias marcadoras de la infancia (Las Primeras Tablas) para finalizar con la construcción de un discurso de carácter moralizante de índole poética como alternativa al (re)conocimiento y cuestionamiento de las leyes asociadas a la vida familiar, religiosa y social (Las Palabras del Fabulador). Este trayecto que realiza el sujeto y que al mismo tiempo vendría a ser un viaje de la infancia a la adultez tiene una serie de implicancias. Por un lado, intenta exponer la falsedad moral de las costumbres adultas poniendo por delante, si se quiere, a los niños y niñas para su protección y resguardo. Por otro lado, este cuestionamiento de las leyes genera una distancia crítica de carácter creativa, cuya potencialidad es la fábula: un discurso otro, con moraleja constrastante, propio de esta forma simple ${ }^{2}$. Ambos movimientos forman parte de un mismo plan: "El objeto de cuidado ético son los niños engañados, desvalidos, abandona-

\footnotetext{
${ }^{2}$ Este concepto lo utiliza André Jolles en su estudio Las formas simples. La fábula de Perrault y su actualización en los hermanos Grimm (que quita la explicitación de una moraleja) corresponden, de acuerdo a la categorización de Jolles, a la forma simple märchen. Esta tiene como virtud, entre otras características esenciales, neutralizar lo trágico y destruir el mundo de la realidad sentida como inmoral mediante una narración cuyo final reestablece el mundo tal como este debiera ser. De ahí, la innegable satisfacción reparatoria que proporciona a los lectores (Jolles, 1972: 215 y ss.). Creemos que en Quezada opera esta misma ética del acontecer que busca mostrar el mundo de los niños como debiese ser. $\mathrm{Si}$ en Las palabras del fabulador se encarga de hacer la denuncia y el juicio, en Astrolabio (1976) se sitúa plenamente en el orden del deber ser, específicamente en las secciones "A la pata coja o poemas que me habría gustado escribir cuando estaba en la escuela primaria" e "Historia de familia", cada una compuesta de 17 poemas que funcionan como estampas de una infancia feliz, desproblematizada y segura. Paradójicamente, esta vivencia de infancia como debiese ser, a nuestro juicio hace perder la fuerza estética conquistada en Las palabras del fabulador.
} 
dos y huérfanos, aunque tengan padre y madre vivos, porque el descuido y la mentira de los progenitores los sitúa en la orfandad" (Sepúlveda, 2001: 257). Teniendo como eje a los niños que se insertan en la vida familiar a través de una experiencia huérfana es que este libro se construye, a través de toda clase de indicios que ayudan a reconstituir el panorama del juicio. Veremos a continuación algunos de estos indicios asociados a esta construcción.

La sección Retrato Hablado comienza con el poema del mismo nombre y con el acto de hablar: "Digo pan / y la mesa extiende su mantel" (11), pero en un abrir y cerrar de ojos ya no existe ni la mesa, ni el pan ni el mantel, "solo el retrato hablado de mi hambre" (11). De entrada situamos a un sujeto que habla y nombra las cosas por ausencia, por carencia, porque estas ya no están o desaparecen, solo aparecen en el decir cuando se intenta dar forma a la experiencia. En este caso, a la experiencia del hambre, palabra que reemplaza a padre si damos cuenta de la frase popular: "retrato hablado del padre". Mediante esta proximidad sintáctica, el poeta genera una carga de sentido semántico: hablar del padre es hablar de un hambre, una carencia, ausencia de alimento espiritual o emocional. De ahí, la necesidad de erigirse como sujeto, dibujar su yo desde la nada, desde la ausencia total, desde un silencio enunciativo solo posible de construirse por el lenguaje, la palabra que nombra y funda su subjetividad y determina su "estatuto lingüístico" de persona inserta en la cultura (Benveniste, 1979: 181) y da (dis)curso a la experiencia. Como señala Lyotard en Lecturas de infancia (1997), el nacimiento y la infancia están allí antes de que uno lo esté y "ese allí en cuestión se llama cuerpo" (44). La poética de Quezada es la poética de un cuerpo adulto que viene a su infancia una vez que tiene la capacidad de articular el discurso sobre lo vivido en esa infancia:

No soy yo quien nazco, quien soy alumbrado [enfanté]. Yo mismo naceré después, con el lenguaje, al salir de la infancia [enfance], precisamente. Mis asuntos habrán sido tratados, decididos, antes de que yo pueda responder por ellos. Y esto de una vez para siempre, y esa infancia, ese cuerpo, ese inconciente se quedarán ahí durante toda mi vida. Cuando me viene la ley, con el yo y el lenguaje, ya es demasiado tarde. Las cosas ya habrán tomado cierto giro. Y el giro de la ley no llegará a borrar el primer giro. Ese primer toque (44-45). 
El sujeto que da pie a este poemario es un sujeto cuya subjetividad ha sido marcada por una experiencia violenta: el hambre, la necesidad, el abandono, y estos son su primer giro o toque. Por eso: "Esto de no tener casa / de no tener sillas para arrimar a una silla" (12). Y peor aún: "Huésped soy en una casa sospechosa / y me ahogo con una cuerda al cuello / que nadie ve y todos tiran" (15). Se trata de un niño ahogándose en el hogar, en su cordón umbilical invisible que nadie ve, pero del cual todos -los adultos, la sociedad, la cultura - tiran. Por otro lado expresa: "Me imponen principios y costumbres" (15). Todos estos indicios nos hablan de un infante que, como el niño descrito por Benjamin, se constituye en el hogar por ser un "huésped errante e inseguro" (Benjamin, 1969: 98), sobre el cual recaen órdenes e imposiciones adultas que buscan su moldeamiento y constitución como sujeto en la cultura. Pero el niño de Quezada se rebela: es consciente de su ahogamiento y hace lo posible para salir de él: "solo cortando el cordón umbilical podrá evitar la sensación del suicidio cotidiano" (Concha, 1968: 490). Para este efecto, habla, desde el adulto que escribe, para constituirse como un sujeto otro en el discurso de la fábula, haciendo emerger su subjetividad discursiva. Como el sujeto infantil de los poemas de Lihn, este niño de Quezada se sabe espectro y organiza su venida para una propuesta escritural de otro orden que no se queda en la traumática e invalidante aparición fantasmal ${ }^{3}$, que no se queda en la mera constatación del horror.

La moral que instaura Quezada, eso sí, trae consigo una paradoja: también pretende ser una propuesta de un orden, una enseñanza normativa intrínseca a toda fábula que escapa a los márgenes exclusivos del discurso poético. La poética de Quezada va contra la ley, pero utiliza un formato literario cuyos mecanismos de escritura pretenden legitimar una ley para un discurso que no se cierra en el lenguaje poético. Su mensaje, podríamos señalar, es un mensaje de cambio poético y social, en base a que sabe que para el crecimiento no solo es indispensable "el silencio de la leche materna / (...): Se necesita también de las palabras” (16). Palabras claras y ordenadas en un discurso poético con trasfondo social. Así, el adulto que habla a través de este niño reclama y recalca las historias y cuentos oficiales de los

\footnotetext{
${ }^{3}$ Para un contraste sobre la figura del huésped fantasmal en ambas poéticas, es posible consultar el trabajo que publicamos en Acta Literaria, 40, 9-28 (2010).
} 
adultos: "Pero yo no entiendo cosas / que de niño me hicieron aprender de memoria" (17)4. Esto da pie para una resignificación de lo aprendido de memoria, sin sentido, y para una revisión del orden asimilado desde el origen, cosa que sucede en la siguiente sección del poemario.

\section{Las tablas inscritas}

Las Primeras Tablas es el nombre de la segunda sección de Las palabras del fabulador. En su polisemanticidad, estas nos hablan de las tablas de Moisés o de las tablas que en la escuela se aprendían de memoria. Pero también, en una recurrencia al habla coloquial, a los primeros pasos, a la asimilación del orden de la vida y a las primeras construcciones de una identidad.

Advertimos una cierta ironía en la vuelta a un origen. El poema que abre esta sección se titula "El visitante" y dice así: "Por el vidrio roto de la ventana / ha entrado una plumilla de cardo: soy un hombre dichoso / visitado por mi infancia" (21). Esta recae en la oposición dichoso/cardo, puesto que sabemos que esta flor es una de las primeras que florecen en primavera, pero tiene como propiedad característica el tener espinas en las hojas y en los tallos. Es decir, una flor que puede herir. Por tanto, esta dichosa infancia no es tal. Parece más bien una infancia amenazada por la herida.

Este inicio de sección signa la atmósfera de los poemas sucesivos marcando la trayectoria del sujeto, cuya subjetividad, sin embargo, va encontrando puntos de fuga para la construcción de una identidad. Así, se suceden los poemas que hablan de una primera carta de amor fallido, el recuerdo del abuelo al ver las espadas y sables del Museo Nacional, el sentimiento que provoca la lluvia, la experiencia del tren que marcó la vida de los habitantes del sur de Chile y la muerte del padre. Esto último se tematiza en el poema titulado "Generación va generación viene" y marca la conciencia de un sujeto que asimila el orden de la existencia: que el ser está destinado

\footnotetext{
${ }^{4}$ Hasta la Reforma educativa de 1998 todavía estaba vigente en las escuelas chilenas y latinoamericanas el paradigma del aprendizaje memorístico, modo de enseñanza que atravesó todo el siglo XX y que marcó a generaciones de niños y jóvenes.
} 
a morir y que la vida se renueva a través de la descendencia. El poema es bello, cargado de ternura en los últimos versos:

Ha muerto su padre

Y mientras lloran sus hermanas

Se va al fondo del patio

A recordar el lugar donde una vez

Recogió un nido caído del cerezo (26).

Ante la muerte el niño siente la necesidad de ir al fondo del patio, vivirlo en soledad mientras su familia llora la partida y recuerda cuando recogió un nido caído del cerezo. Es decir, cuando se preocupó de la vida frágil de un pajarito. El sujeto de este poema se siente ahora como ese pajarito, desvalido, fuera de su nido. El sentimiento de huerfanía es total, desolador.

Esta memoria de infancia que el poeta ha dado a conocer finaliza en esta sección con el poema que le da título. Aquí, el hablante señala:

Porque se hinchaba la madera de la casa en los inviernos

Escribí con los diez dedos de las manos:

La mañana vacía los tarros de la leche

Y bastaban estas palabras

Para encontrar hasta la herradura

Que una vez perdió el caballo del panadero (31).

El sujeto oficializa su nacimiento en la escritura, formalizando en las tablas la magia de su quehacer: escribiendo con las dos manos que "se llenaban de agua bautismal" (31) una frase que es suficiente para encontrar lo perdido y suficiente para nacer, a través del lenguaje, en una discursividad poética. Con esto, se inscribe en una escritura fundante, enraizada en la infancia que declara: "Nos pertenece la sombra de estos cerezos" (31) En esa memoria fundacional, el sujeto instaura su genealogía poética. Las tablas quedan inscritas, talladas. A continuación, marcará distancia con otras tablas, las del orden cultural.

${ }^{5}$ Las cursivas son del original. 


\title{
Justicia y reparación
}

La tercera sección de Las palabras del fabulador, titulada del mismo modo que el poemario, da cuenta de un marco normativo. En este apartado, el hablante tematiza en gran parte las faltas a la norma cristiana occidental, a los mandamientos católicos y su corporización en los pecados capitales. Cuestiona su imposición y el hecho de que su transgresión dé cabida a un castigo. Con esto, se vive una contradicción: pareciera que no hubiera mejora al pasar de niño a adulto.

Los poemas que componen esta sección están dedicados a los mandamientos de Moisés (No matarás, No robarás), a los pecados capitales: la gula, el adulterio, la vanidad, etc., y a las normas de conducta social. Pero al mismo tiempo que se las enuncia, se las transgrede. Por ejemplo, en el poema "La conducta":

\author{
Dice su primera palabrota \\ A la hora del almuerzo \\ Y se encoge de hombros \\ Como si tal cosa \\ Y el gato le golpea sus piernas con la cola \\ Y todos miran alrededor de la mesa \\ Y sueltan su carcajada \\ Menos sus padres \\ Que no han podido comer su huevo de vergüenza (40).
}

El niño sabe que ha obrado mal, pero se encoge de hombros y el gato pareciera advertirle de la situación. Por tratarse de un niño, los comensales solo atinan a reír, menos los padres, quienes se avergüenzan de la conducta de su hijo. Más allá de lo anecdótico de la situación, el hablante pareciera advertirnos de lo incómodo que se siente en el hogar y con el tipo de enseñanza que recibe, sometido a estos "principios y costumbres" que comentábamos en un comienzo y que no le hacen sentido. Esto genera una incipiente rebeldía que busca exponer la falsedad de este orden moral, cuestionando de paso su propio accionar automatizado. Otro ejemplo es el poema "El hijo natural", donde el hablante expresa que no se atreve a preguntar por qué una mujer que no tiene marido está tendiendo en los 
alambres unos pañales blancos. Sabe que la escena marca un estigma: la mujer ha concebido fuera del matrimonio y eso, según la legislación chilena de la época, corresponde a un "hijo ilegítimo", figura legal entroncada en la cultura chilena ${ }^{6}$ y estigma social de indecencia, deslegitimidad y malas costumbres desde el punto de vista del código civil y de cierta clase conservadora.

Los últimos cinco poemas del conjunto marcan preocupaciones atingentes a la sección y al poemario en su conjunto, otorgando un cierre poderoso a estas problemáticas. En "Mi primera soledad" el hablante se interroga una vez más por su origen y les pregunta a sus padres cómo fue el día de su nacimiento, pero estos no responden y siguen en sus ocupaciones. Entonces, el niño dice: "Dímelo tú / pequeño gusano que vienes en mi choclo: / ¿Llovía o no el día de mi nacimiento? / Decididamente mis padres no tienen remedio" (43). Con esto, marca una distancia insalvable con sus padres, distancia entre infancia y adultez que es la que propone esta poética: los padres, en su mutismo, demuestran incapacidad para recrear (fabular) sobre un momento crucial de la vida de un niño que quiere saber cómo llegó al mundo; el niño, en cambio, tiene plenas facultades para entablar comunicaciones imaginarias. Pese a esto, el silencio de los padres se vuelve opresivo para este niño solitario, a quien no le queda más remedio que recurrir a un triste soliloquio con un gusano. Este, además, como símbolo de muerte y corrupción termina generando una distancia temporal en la conciencia del sujeto, ya que rápidamente conduce la pregunta de este niño por un origen desconocido a un final que sí es sabido, porque ya ha tenido experiencia de la muerte. Es decir, el silencio de los padres (el retrato hablado de su hambre) genera un desplazamiento metonímico que lo sitúa en la muerte. El silencio como expresión de muerte.

${ }^{6}$ La ley que no reconocía a los niños nacidos fuera de la institución del matrimonio fue derogada muy tardíamente dentro de la cultura chilena, en 1998, bajo el gobierno de Eduardo Frei Ruiz Tagle. Su vigencia tuvo 140 años y negaba al "hijo ilegítimo" o huacho derechos civiles y sociales, tales como el derecho a la herencia, a recibir alimento y a tener parentesco. Estos eran de dos categorías, concebidos fuera de la institución del matrimonio: los "naturales" (reconocidos por un progenitor o por los dos) y el "ilegítimo" propiamente tal (no reconocido por nadie). Disponible en http://www.latinamericanstudies.org/ chile/nacidos.htm 
Una niña que lee un libro de Historia Antigua, mientras en el techo de la casa dos gorriones se despluman y procrean es el escenario del poema "La inocencia". Cuando llega el padre y baja las persianas, la niña cubre su cara con el libro y llora. En el citado artículo de Sepúlveda, la autora señala que este poema da a entender un caso de violación como historia antigua que revive en la niña: "La reiteración de la palabra 'procrear' potencia todo el poema, dando una pista al lector, a fin de que interprete el verso 'cerrar persianas' como un deseo de ocultar lo que sucederá en la habitación" (Sepúlveda, 2001: 259). Resulta interesante, en este poema, cómo Quezada desnuda solapadamente los "principios y costumbres" sociales, provocando sobre ellos una sanción. En este sentido, la fábula que construye intenta contrastar, además, la intrahistoria que signa los trayectos de vida de los sujetos con la historia oficial, la norma de la cultura y las costumbres arraigadas en ciertos enclaves sociales. La historia de la infancia ha estado plagada de abuso de menores y en la historia de Chile también ha sido una práctica extendida. La historia de la infancia "es una pesadilla de la que hemos empezado a despertar hace muy poco. Cuanto más se retrocede en el pasado, más bajo es el nivel de la puericultura y más expuestos están los niños a la muerte violenta, el abandono, los golpes, el terror y los abusos sexuales" (De Mause, 1994: 15). Como el historiador, el poeta también da cuenta del signo de su tiempo y denuncia lo que sucede cuando se bajan las persianas. Ante la historia anónima de la niña, de poco y nada sirve la Historia Antigua que la niña repasa mentalmente. La historia mínima es rescatada en contraposición a la historia oficial, para reparar en la cultura aquello que esta omite, oculta y no escribe/inscribe en sus tablas.

La preocupación por el cuidado y salud de los niños en esta fábula se hace palpable también en un poema como "La orfandad":

La gente llega con sus cartillas en la mano

Es domingo. Y se pierde la cabeza

Un niño corre

Los caballos esperan a la entrada del hipódromo

Como buenos caballos

Y una pelota de goma rueda por sus patas (45).

Así como los adultos pueden "perder la cabeza" en las apuestas de las carreras de caballo, un niño la puede perder entremedio de las patas de los 
animales, por descuido. Pareciera que una cosa fuera consecuencia de la otra, signo de esta orfandad que atraviesa la trayectoria de los niños de la fábula, a partir de la cual se intenta enseñar a los grandes que no pueden perder de vista a los niños en espacios públicos. Con esto, el poeta intenta hacer un acto educativo de advertencia, de carácter preventivo y los lectores aprehendemos la moraleja.

La voz de estos textos pareciera querer dar fin a las costumbres de los adultos de contar cuentos, como diciendo: hay que hablar con la verdad. Como frase popular, "contar cuentos" refiere a engaño. Entonces, recurriendo a la circularidad de la existencia, el niño que ahora es hombre es el que cuenta un cuento a la madre, tal como leemos en "La herencia":

La madre engaña a su hijo con un cuento

Y el plato de sopa queda limpio

El hijo crece

Se hace hombre

Se casa. Y tiene un hijo

Y el hijo engaña a su madre con un cuento

Y el plato se ensucia con el llanto (46).

En la polaridad limpio/sucio, el hablante remarca su visión. Tras el cuento, a los ojos del niño, queda todo limpio; se olvida la mancha, aquello que motivó contar el cuento. Pero a los ojos del adulto, el plato queda sucio, manchado por el engaño. El hablante aquí enseña el verdadero rostro del niño y del adulto contrastados en torno a una misma situación. Como dos caras de una misma moneda, aquí se refuerza la idea de que lo que los niños finalmente heredan de sus padres es la mentira, el aprender a mentir, desvelando con esto la hipocresía de la vida social, de las (malas) costumbres familiares. Todo esto, en conjunción con lo expuesto hasta aquí, genera la siguiente reflexión: si sus padres le hubiesen revelado su origen y no hubiesen callado, si los principios y costumbres hubiesen sido otros, tal vez otra identidad tendría este sujeto o su daño sería menor. La fábula, por tanto, cumple una misión de sanación: es un acto reparatorio, un acto de justicia poética. 


\title{
Situarse fuera de la ley
}

El corolario que Jaime Quezada da a sus palabras de fabulador se encuentra herméticamente cristalizado en el poema "Fábula de los sepultureros". Encontramos en este texto un acto tardío de justicia que viene a poner las cosas en orden:

\author{
No cabe el ataúd \\ En la fosa que abrieron los sepultureros \\ (Qué culpa tiene el muerto)
}

Los sepultureros cavan una fosa mayor

Y la llenan de flores

Y la cubren toda con la tierra

Pero olvidaron poner el ataúd

(Qué culpa tiene el muerto) (47).

Encontramos en este críptico poema una multiplicidad de posibles lecturas. Una interpretación que nos hace sentido, al alinearlo con los poemas anteriormente aquí expuestos, relaciona la fábula con la muerte. Habría allí, en la muerte, un tragicómico error u olvido que exculpa al muerto, marcando su inocencia, su no culpa, respecto a una acción ejecutada por otros. Es por esto que una lectura de este poema permite señalar que el muerto es un niño y los sepultureros son los adultos. Y que el niño, intrépidamente, ha logrado zafarse de su entierro para aflorar en el presente adulto de la escritura. Para el adulto, el niño es un ataúd al que se le llena de flores, pero el niño se niega a ser enterrado y queda fuera del plan, se escapa, con un traje que no queda a su medida. Pero también es plausible interpretar lo siguiente: que en realidad no hay muerto, que no hay nadie a quien enterrar, que no es posible enterrar la vida, que el infante situado fuera de la ley no es enterrable, porque precisamente está fuera de la ley, más allá del bien y del mal, más allá de la dialéctica vida/muerte, antes que el lenguaje, antes que la cultura que se quiere imponer.

Independiente de una lectura u otra, queda clara una cosa: por más que los adultos intenten moldear la vida de los infantes, fracasarán siempre, porque el niño -inocente, no sabe nada del bien ni del mal- se niega a ser 
cavado en ese discurso socializante y normativo. La vida que construyen los adultos (su fosa), con sus normas y costumbres, es factible de ser aplicable por ellos, los sepultureros, los enterradores de la infancia, únicamente como imposición, como ley. Porque en ese plan el niño no calza, no cabe, porque ha nacido antes que la ley: en la mudez, en el silencio, el hambre, el abandono, la orfandad e incluso la muerte.

Leído de esta manera, el niño de este discurso poético escrito desde la adultez signa la imposibilidad de sepultar la infancia. Y a través de la construcción de una fábula de infancia cumple la función catártica de liberar a los niños de toda responsabilidad legal, de toda falta, porque ellos han nacido antes de la ley, fuera de la ley. La culpa de la Cultura, encarnada en los padres, es la de signar el crecimiento con el silencio opresivo y las imposiciones de principios y costumbres, de entorpecer y ennegrecer un armónico desarrollo de la niñez. Para la ley de la cultura este proceso resulta inevitable: "la ley exige la muerte de una inocencia culpable, pero exige también un tiempo de muerte, y que la inocencia agonice" (Lyotard, 1997: 49). Por eso, en este sentido, creemos que lo valioso de la propuesta estética de Las palabras del fabulador es que vendría a ser una suerte de sumario judicial: el expediente de un juicio a la ley de la cultura que ha matado la inocencia por la culpa indiscutible de los infantes de haber nacido antes de la ley, ilegítimamente. El ser un hijo "natural" (que parcialmente se reconoce) es algo que no ha podido ser borrado de la memoria de este sujeto que procura restituir la infancia. Ha sido su marca, su giro, su toque. Pero con esta poética, a ese niño, a los niños, al menos poéticamente, les hace justicia.

\section{Referencias}

Benjamin, W. (1969). Escritos. La literatura infantil, los niños y los jóvenes. Buenos Aires: Nueva Visión.

Benveniste, É. (1979). De la subjetividad en el lenguaje. En Problemas de lingüística general (pp. 179-187), Vol. 1, México: Siglo Veintiuno.

Berrie, J. (2006). Peter Pan. Buenos Aires: Alfaguara.

Campos, J (1987). La joven poesía chilena en el período 1961-1973. Concepción: Lar.

Concha, J. (1968). Entre la infancia y las leyes. Atenea, 421-422, 490-493.

De Mause, L. (1994). Historia de la infancia. Madrid: Alianza. 
Lyotard, J. F. (1997). Lecturas de infancia. Buenos Aires: Eudeba. Jolles, A. (1972). Las formas simples. Santiago: Universitaria.

Quezada, J. (1965). Poemas de las cosas olvidadas. Santiago: Orfeo. . (1968). Las palabras del fabulador. Santiago: Ediciones Alerce. . (1976). Astrolabio. Santiago: Nascimiento.

Salazar, G. (2006). Ser un niño huacho en la historia de Chile (siglo XIX). Santiago: Lom.

Sepúlveda, M. (2001). Jaime Quezada: Líneas de fuga de una identidad sin fronteras. Anales de Literatura Chilena, 2, 247-264. 